\title{
Camouflage of Seeds, a Control Method of the Bird Mortality in Grain Crops
}

\author{
Alexandre de Almeida ${ }^{1}$, \\ Hilton Thadeu Zarate do Couto 2 and Álvaro Fernando de Almeida ${ }^{3}$ \\ ${ }^{1}$ National Service of Industry, Department of Environmental Resources, \\ ${ }^{2,3}$ University of São Paulo, Department of Forestry, \\ Brazil
}

\section{Introduction}

This chapter discusses the development of a mitigation measure against impacts caused by the ingestion of poisoned seeds by insecticides like carbofuran and carbosulfan in wheat, corn and rice fields.

In accordance with Brazilian Federal Decree no 4.074 of January 2002, agrotoxins should be added to seeds mixed with dye to avoid the risk of being ingested by humans. The toxic dye rhodamine B, whose reddish-purple colour has been used for this purpose, it's apparent and attractive to granivorous wild birds such as Columbidae and Icterinae.

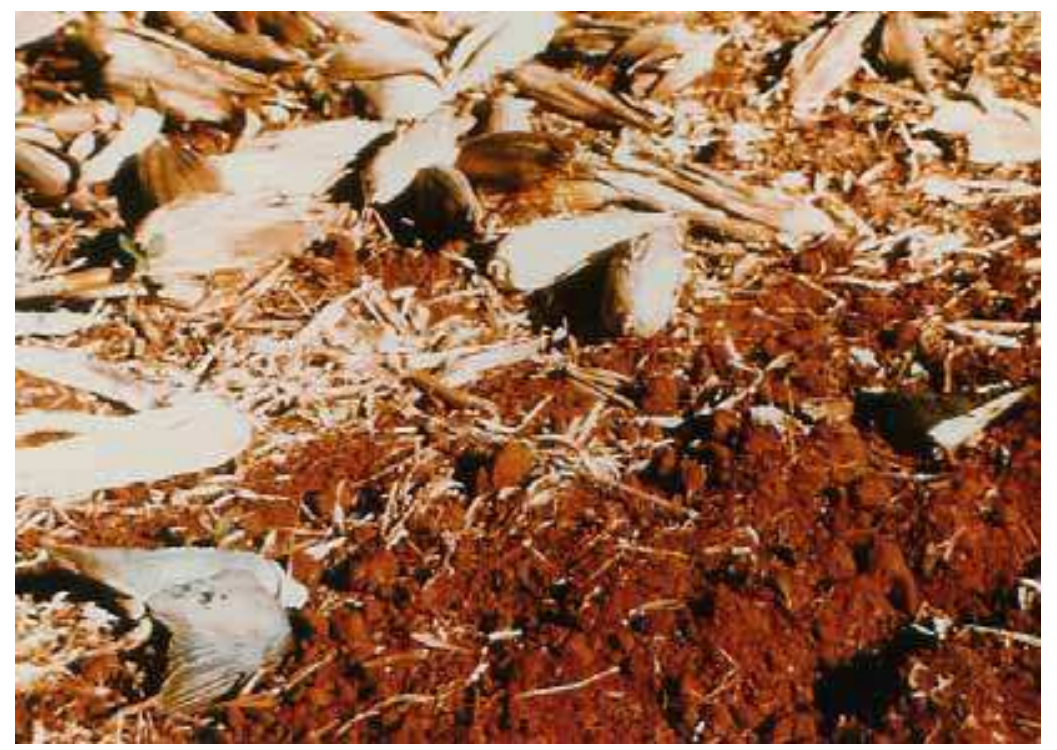

Fig. 1. Eared-dove (Zenaida auriculata) fatally poisoned by eating weath treated with carbofuran and rhodamine B. Harvested crops are attractive to the granivorous birds and may increase the mortality rates during the next sowing. 
Seeds treated with carbofuran and rhodamine B, which are not completely covered during mechanical seeding, are picked up by granivorous birds foraging for food. This leads to direct mortality (Figures 1, 2, 7, 11) by deliberate ingestion or secondary poisoning if predators ingest these poisoned preys. This problem is not confined to Brazil but is also an issue in several countries where seeds covered with agrotoxins are used.

Most measures to mitigate the damage caused by birds attacking the production and / or mitigation of the mortality of birds by the use of pesticides, has been to repel the birds of the site, avoiding the consumption of seeds by acoustic, tactile, visual and/ or gustative repellents. However, the use of repellents spend resources of high operational and financial costs, has not produced satisfactory results and often violates humanitarian principles causing injury and suffering to the birds.

Despite these findings and public criticism, several recent studies evolve in this direction (Tobin, 2002), seeking chemical repellents and/ or color repellents to reduce the damage to production and reduce the risk of pesticide poisoning wildlife (Avery, 2002).

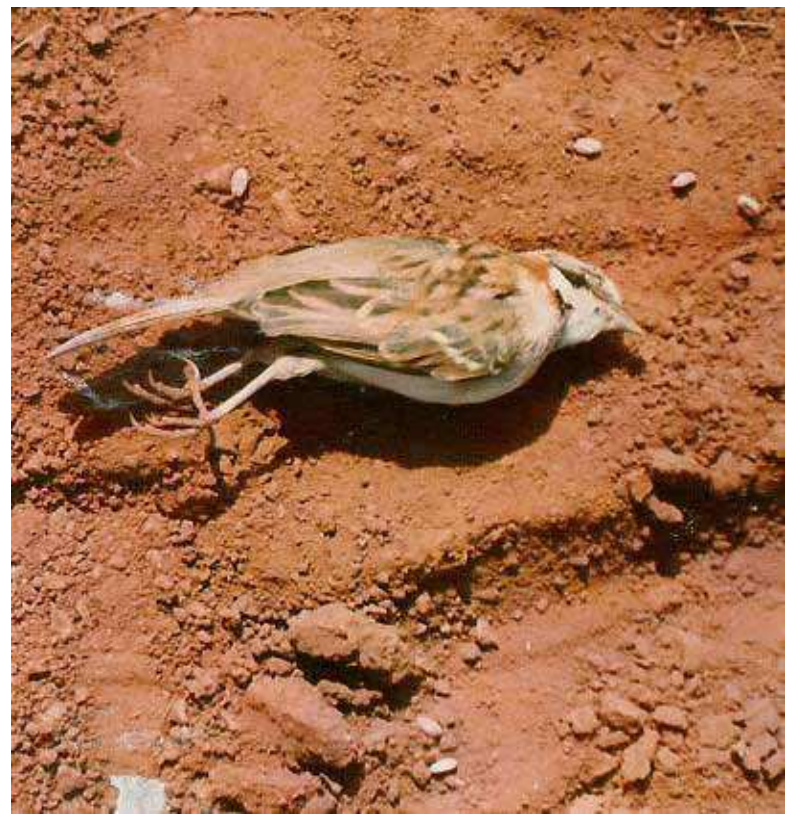

Fig. 2. Rufous-collared sparrow (Zonotrichia capensis) killed by eating poisoned wheat seeds treated with carbofuran and rhodamine B, which can be seen beside the bird.

Poorly developed sense of taste is a plausible hypothesis to explain the limited results of some authors, using chemical repellents in the absence of alternative food sources for birds: Avery et al. (1998) with anthraquinone, Moran (2001) metil antranilato, Almeida et al. (2010a) with carbosulfan, Almeida \& Almeida (in press) employing carbosulfan and methiocarb. Taking the example of these cases, when grain stained with 'aversive' colors were used, there were also ingestion rates (Avery et al., 1999, Hartley et al., 1999, 2000) which can result in high mortality rates in situations where the density of birds is high. The combination of chemical repellents for aversive colors has generated more effective results as a method of controlling agricultural damage (Avery \& Mason, 1997; Nelms \& Avery, 1997). 


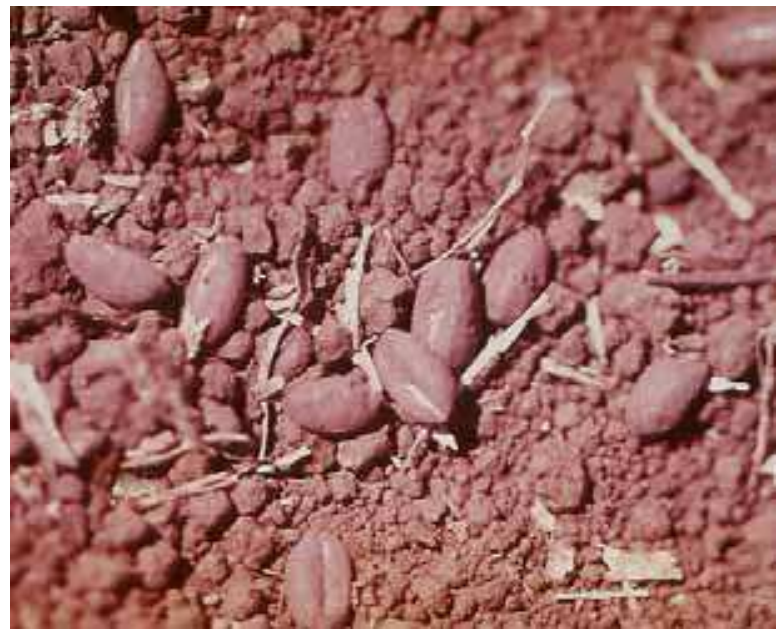

Fig. 3. Camouflaged seeds in the absence of irregularities in the surface soil can be more conspicuous to the birds. Note that the color and roughness of the camouflage, conferred by the dye powder, help hide the seeds in the soil.

However, seeds with aposematic and/ or aversive colors become very conspicuous, which may represent a high risk of mortality. This can be inferred, considering that, despite the lack of consumption of blue color seeds in some experiments (Hartley et al., 1999, 2000, Almeida et al. 2010b) the use of carbofuran in the granular formulation of the same color has been banned in Virginia, USA and Canada, due to bird mortality caused by direct ingestion of the product (Almeida et al., 2010b).

Moreover, there has been no communication observed between poisoned birds and healthy ones, that could stop the consumption, even when expressive mortality rates occur and in the presence of obvious agonistic behaviors caused by the ingestion of seeds treated with carbofuran, methiocarb carbosulfan or in combination with conspicuous colors such as beige and red (Almeida et al., 2010a; Almeida \& Almeida, in press). In these experiments, it was notew orthy that gustative repellents (carbosulfan and methiocarb) were superseded by the fact that carbofuran has the unpleasant distinction of being so hazardous to wildlife, that it simply cannot be effectively regulated or managed accordingly without mortality risk occur (Richards \& Mineau, in press). However, the camouflage of seeds (Figures 3 and 4 ) has been presented as a method capable of significant reducing the mortality of birds in comparison with the traditional way of planting seeds treated with carbofuran and rhodamine B, and compared to other possible mitigation alternatives, such as gustative repellents and/ or conspicuous colors, which could be aposematic, leading to neophobia and aversion by birds (Almeida et al., 2010a, b; Almeida \& Almeida, in press).

A cryptic species is one whose color and/ or morphology resemble relevant aspects of the habitat where it lives. The ecological literature is rich in documentation of cryptic species that can survive in the presence of predators. The ability of many species of reptiles, amphibians and fish to change their pigmentation according to the substrate where they are found, it is indicative of the remarkable evolutionary success of cryptic behavior, which is common in nature.

The Bionics, defined as: 'Living creatures science-based ', which one of the most oldest and best know applications is the camouflage, whose inspiration would come from the ability of 
cryptic animals such as zebra and chameleons. Camouflage comes from the French word 'camoufler' which means to disguise or conceal through a disguise and its evolutionary significance has been gaining wide scientific support as a mechanism that reduces the risk of detection (Merilaita et al., 1998, Zug et al. 2001; Merilaita, 2003, Schmidt et al., 2004, Frankel et al. 2004; Merilaita \& Lind, 2005, Cuthill et al., 2005).

The principle of camouflage inspired and guided the development of this research. Seeds of wheat, corn and rice, when treated with systemic pesticides, would receive dyed camouflage, making them similar to the soil where they were planted. This cover would preferably be processed on the same machine that performs pesticide treatment, moreover, it could not impair the mechanical planting or germination. The camouflage should have low operational and financial cost, as well as been non-toxic. Thus, seeds that were not buried by the planting machine, remaining dangerously exposed to granivorous birds, would count with a camouflage whose effectiveness would be favored by organic matter not decomposed, by the irregularities of the soil, and by the contrasts between light and shadows on the soil surface, even though the birds actively seeked them on the ground.

Birds attack the agricultural fields because they are abundant sources of food readily accessible, requiring low energy expenditure. If food becomes difficult to find, to ingest, and to digest, birds will spend more time and energy to forage. Having them difficulty to maintain a certain rate-making energy, the theory of optimal foraging predicts that animals will look for another food source (Avery, 2002, Begon et al., 2006).

The aim of this paper is to present the method of concealment of seeds and how it was designed, with respect to the material tests and seed germination. Results obtained from these assessments show that camouflages can increase the germination rate of seeds and that 'home-made' forms of camouflage can be as efficient, if not better than camouflage produced by industrial processes. Also, camouflage do not need high operating or financial costs, it can be applied to seeds using the usual machinery of seed pesticides treatment on commercial scale plantations.

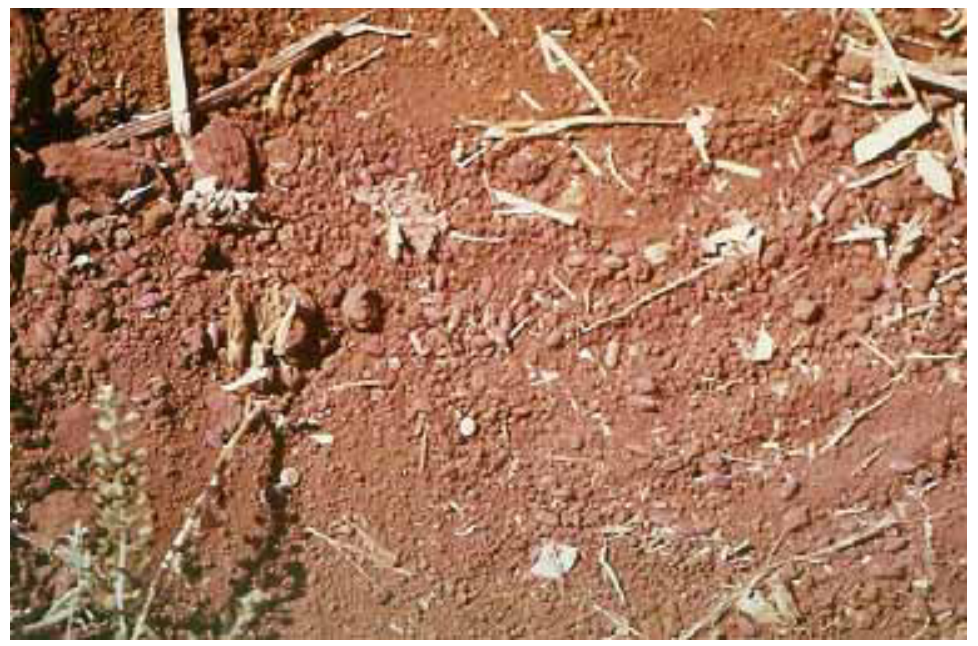

Fig. 4. Camouflaged seeds can be visible, representing risk of poisoning for birds, if it were not completely buried and were seeded outside the plowed soil of the planting, or in absence of non decomposed organic matter on the soil surface. 
However, before, results of research on the effectiveness of the forms of mitigation that has been tested, among which different types of camouflage, whose forms of development and germination tests are being discussed here, will be presented.

The mitigation method will be contextualized regarding the impacts caused by the usual ways of planting wheat and corn with seeds poisoned by carbamates pesticides, such as carbofuran and carbosulfan. Then we will present a discussion on results obtained with different types of ingredients, used in preparing camouflage, regarding the effectiveness of camouflage, cover durability and environmental factors that influence the trial in agricultural fields.

Finally, there will be a discussion about determinant factors of the camouflage effectiveness in some species in experimental conditions, explaining the results obtained by this research.

\section{Methods of controlling bird mortality}

An study consolidating three experiments was conducted in Paraná and São Paulo States to evaluate if camouflaged seeds could minimize the mortality of wild birds, caused by the ingestion of commercial seeds treated with pesticides and rhodamine B (Almeida et al., 2010a). When put all together, the three experiments were summing up to $15,896 \mathrm{~kg}$ of seeds, sowed in 111.46 hectares. Alternative strategies for reducing mortality, like the use of carbofuran without rhodamine B and the use of carbosulfan. Carbofuran without rhodamine B gives a 'beige' hue to seeds and could make them less attractive to birds, representing economic savings at planting. Carbosulfan, a carbamate with insecticidal and nematicidal properties and with a lethal dose circa 20 times weaker than carbofuran, could act as a chemical repellent if the birds were able to link the poisoning symptoms to the food, halting the consumption before dying.

Experiments in rice and wheat plantations were performed in regions where mortality of birds, coming from the ingestion of seeds treated with pesticides, was reported by farmers and they were performed in the planting seasons, when numerous flocks of birds were present.

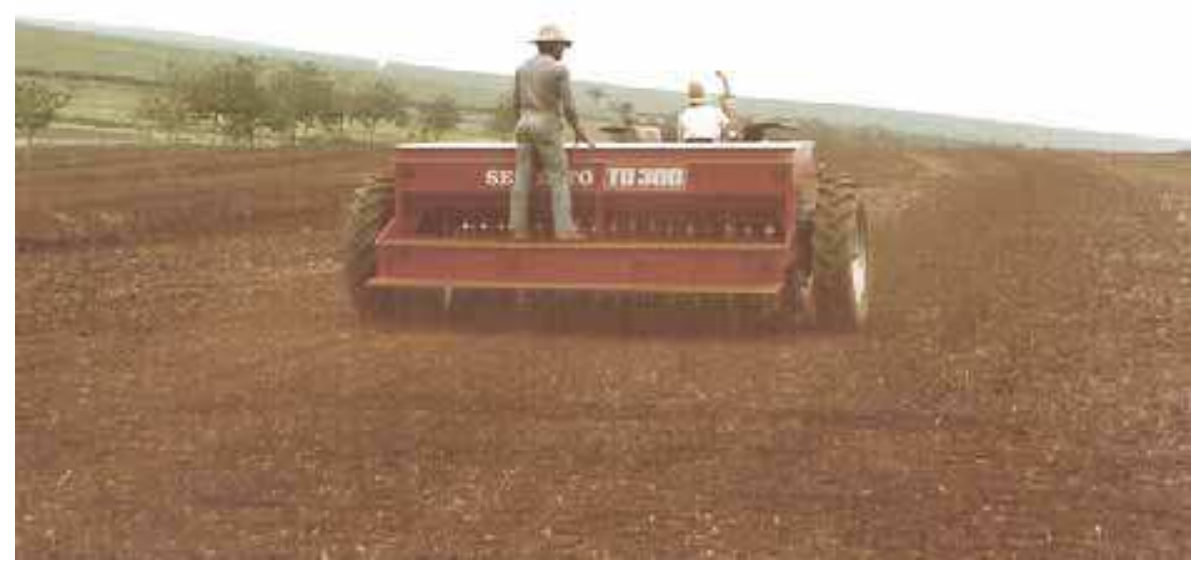

Fig. 5. Installation of an experiment of planting in commercial scale using seeds poisoned with carbofuran. 
The powdered brown-colored dye used in to camouflage the seed was obtained through mixing red, black, blue, brown and yellow powdered dyes, reaching a hue similar to the soil samples previously gathered. The liquid dye used in the other camouflaging was obtained by mixing red, blue, yellow, black and brown pigments in water, and then adding the slurry to the carbofuran syrup in proportions which allowed a proper camouflage to match the region's soil color. The process of camouflaging seeds was performed in the same machine used in the treatment of seeds with carbofuran or carbosulfan.

For treating the seeds, carbofuran in a concentrated suspension of $350 \mathrm{~g} / \mathrm{l}$ was used. The dosage of carbofuran used for wheat or rice seeds was 21 for $100 \mathrm{~kg}$. Carbofuran's toxicity (human $\mathrm{LD}_{50}=8-12 \mathrm{mg} / \mathrm{kg}$ ) was so high that small ( $\left.40 \mathrm{~g}\right)$ and medium-sized birds ( $120 \mathrm{~g})$ ingesting seeds from the experiment often died in situ. Sowing was conventional in dry land, made by a tractor-mounted gravity seed drill implemented with a seed drill over plowed soil in the traditional planting system (Figure 5).

The tested treatments were disposed in parcels no further than $700 \mathrm{~m}$ away from each other. The amount of seeds in parcels and among treatments was balanced. The average plot size was 8.54 hectares $(n=6$; standard deviation $=7.8)$, and there were $144.2 \mathrm{~kg}$ of seeds per hectare. Two searches for dead birds were made per day in every parcel. The searches parties were composed of two, three or sometimes four people walking slowly $(\sim 3 \mathrm{~km} / \mathrm{h})$ or in a pick-up truck $(\sim 5 \mathrm{~km} / \mathrm{h})$ and were gathered within and around the parcels (Figure 6 ).

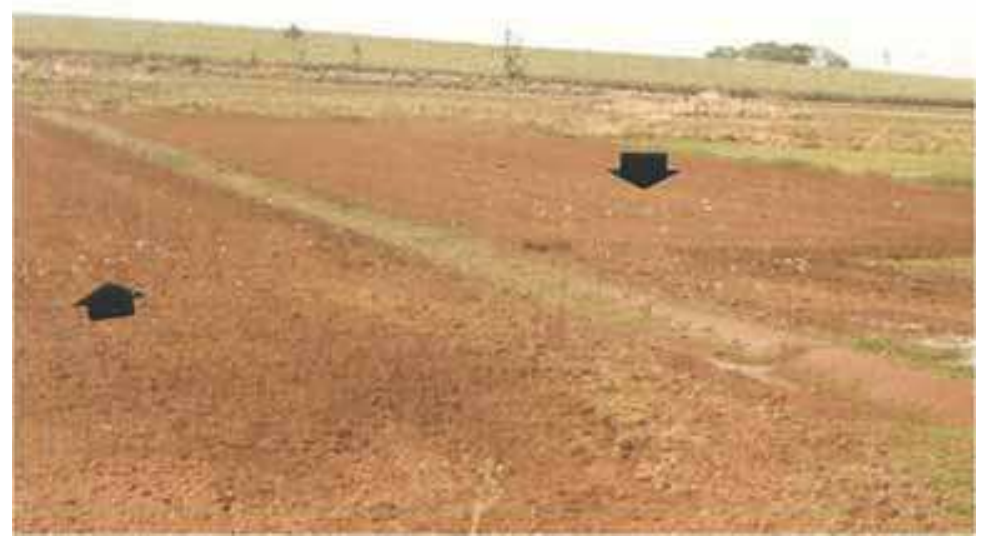

Fig. 6. Birds feeding on seeds poisoned with carbofuran in a experiment of planting.

Bird carcasses were collected and identified. The food present in the digestive tract of bird carcasses was collected separately as it follows: i) crop and esophagus; ii) proventriculus; and iii) gizzard (Figure 7). The seeds from each treatment were counted. The numerical variations from dead birds and consumed seeds between treatments were checked with analysis on variance, considering days of experimental exposure as repeated samples. Birds which were able to ingest seeds from more than one treatment were excluded from the analysis.

The Experiment 1 was conducted using wheat seeds, and the treatments were: i) red seeds treated with carbofuran and rhodamine B; ii) brown seeds camouflaged with powder dye, treated with carbofuran. 
The total experimental area consisted of 10 ha, divided into 1 ha parcels. Five hectares were assigned to each treatment. The amount of seeds in parcels and among treatments was balanced. A total of $1,350 \mathrm{~kg}$ of seeds were used.

Experiment 2. The treatments applied to the rice seeds were: i) red seeds treated with carbofuran and rhodamine B; ii) brown seeds, camouflaged with powdered dye and treated with carbofuran; iii) red seeds treated with carbosulfan and rhodamine B.

For treating the seeds, powder carbosulfan, in a concentration of $350 \mathrm{~g} / \mathrm{kg}$, was used; the dosage was $3 \mathrm{~kg}$ powder every one hundred of seeds. Carbosulfan toxicity for humans was $\mathrm{LD}_{50}=212 \mathrm{mg} / \mathrm{kg}$. Treatments were made to seven parcels of $0.26 \mathrm{ha}$, adding up to $5.46 \mathrm{ha}$. $100 \mathrm{~kg}$ of seeds were used per hectare. The amount of seeds in parcels and among treatments was balanced.

Experiment 3. The following treatments, applied to the wheat seeds, were tested: i) red seeds treated with carbofuran and rhodamine B; ii) brown seeds, camouflaged with liquid dye, treated with carbofuran; iii) beige seeds, treated with carbofuran without rhodamine B; iv) brown seeds, camouflaged with powder dye, treated with carbofuran.

The total assay area was 96 ha, divided into four equal parcels of 24 ha, each one receiving $3,500 \mathrm{~kg}$ of seeds related to the treatments ( $145 \mathrm{~kg} / \mathrm{ha})$.

The mortality mounted to 296 birds, distributed into 11 species. Eared doves were the most numerous victims, with 263 deaths. The consumption of camouflaged seeds was lower than that of commercial seeds treated with rhodamine. The mortality caused by seeds with rhodamine was higher than the one caused by camouflaged seeds. When powder dye camouflaging was used, the mortality range decrease in 75.5 to $100 \%$, and the range of consumption decrease in 57.4 to $99 \%$, relative to the other treatments.

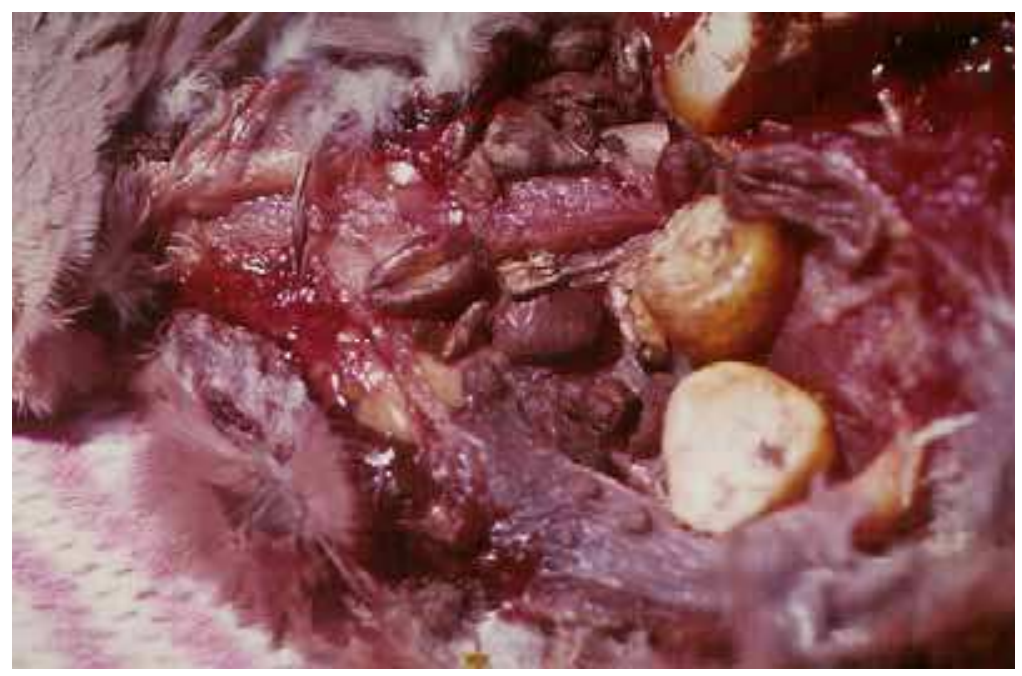

Fig. 7. The dissection of the Ruddy ground dove (Columbina talpacoti), showing one wheat camouflaged seed, which killed the bird. This bird was one of the 73 victims who died with only one seed in the crop, poisoned early in digestion.

The brown color and the powder dye, rich in iron oxide, decrease the spectral reflectance (Hartley et al., 2000; Demattê et al., 2003; Espig et al., 2005; Almeida, 2006) of seeds in the wave lengths visible by the Passeriforms and Columbidae (Hart, 2001), making them similar 
to the soil. In addition, camouflaged coating, made with the powder, presents an opaque surface and, for this reason, has less shine than seeds treated with rhodamine, being less conspicuous (Schmidt et al., 2004; Cuthill et al., 2005). Besides, it is possible that there wasn't search image for brown seeds, and in accordance with the optimal foraging theorem, greater energy would be required to consume and locate such seeds (Avery, 2002; Begon et al. 2006). However, the ingestion of small grits to help crush foods is a common aspect in the behavior of several bird Families (Sick, 1997). So, it is possible that brown-dyed seeds are less removed due to a set of factors linked to the camouflaging phenomenon like background match, avoiding well defined contours and color contrasts (Merilaita 2003, Frankel et al., 2004, Schmidt et al., 2004) and not only due to the aversion to the brown color, as tested by Hartley et al. (1999, 2000). They tried blue and brown with relative success at avoiding the consumption of poisoned grains by birds, suggesting such colors would cause aversion.

The notable ingestion of red seeds suggests that this color, attributed by rhodamine B, is not aversive, but attractive (Schmidt et al., 2004; Cuthill et al., 2005), which is in contradiction to the findings of Avery \& Mason (1997) and Nelms \& Avery (1997). This color's spectral behavior, in the wavelengths visible by the birds, is similar to yellow and orange (Schmidt et al., 2004), which are contrasting and conspicuous and similar to beige. This may explain the high consumption of seeds treated with carbofuran without rhodamine $B$. Thus, whether the reddish hue from rhodamine $\mathrm{B}$, or the beige color, coming from the syrup of carbofuran without rhodamine $\mathrm{B}$, there is a higher probability of birds detecting and ingesting less camouflaged seeds.

The replacement of carbofuran with carbosulfan also appeared to reduce mortality, but carbosulfan mortality is thought to have been underestimated because of the apparent movement of affected birds after exposure. Besides, the possible carbosulfan action as a gustative repellent was not checked and, in addition, birds intoxicated by carbosulfan vulnerable to predator attacks - were able to reach shelters, like forest reserves. Effects of pesticides over the agricultural matrix may propagate through forest fragments, affecting negatively its quality and aggravating the problem of habitat fragmentation, one of the main causes of the biological diversity erosion. These aspects are contrary to the use of carbosulfan and other products, which are up to 20 times less toxic than carbofuran, for the treatment of seeds or as gustative repellents.

The authors had concluded, if seeds treated with pesticides must receive a different color to prevent accidents with humans, the camouflaging method may be used for mitigating the mortality of birds in plantations, substituting rhodamine B (Almeida et al. 2010a).

Another study focusing on mitigation methods was realized consolidating two experiments, witch compares the environmental impacts associated with the use of carbofuran, carbosulfan and methiocarb-treated seeds, with the latter two carbamate compounds being considered as alternatives to carbofuran, and all coloured with Rhodamine B (Almeida \& Almeida, in press). Methiocarb (Mesurol) also is a carbamate insecticide, causes vomiting and paralysis when ingested by birds, acting as a secondary chemical repellent (Calvi et al., 1976; Dolbeer, 1994).

The rice and wheat experimentation occurred in similar conditions of bird abundance, in the same geographical region, and using equals sowing method and carbofuran/ carbosulfan treatments of the anterior study. Likewise, the data collect method and the analysis were the same. The experiments were done with $664 \mathrm{~kg}$ of seeds, sowed in 5.74 hectares. A comparison between the number of deaths consistent with ingesting seeds treated with carbamates was made with the treatments: in the first rice trial: i) carbofuran and 
Rhodamine B, ii) carbosulfan and Rhodamine B; and in the second wheat trial: i) carbofuran and Rhodamine B; ii) carbosulfan and Rhodamine B; iii) carbofuran and Rhodamine B plus methiocarb. Methiocarb was added to the seeds, after they received treatment with carbofuran and Rhodamine B. The dose of methiocarb powder was equal to $1 \mathrm{~kg}$ for each $100 \mathrm{~kg}$ seeds.

The resulting mortality of this experiment mounted to three species, distributed into 314 birds, which 308 were Eared Doves deaths. In the first trial plots, where seeds treated with carbofuran were sown, 109 birds were found dead, and in those treated with carbosulfan, 40 were recovered. These results differed significantly, suggesting that a greater mortality was caused by carbofuran, and that the use of carbosulfan may lessen the impact of grain farming on wild birds. In turn, data clearly showed that carbosulfan use will still result in notable mortality. Further, some birds were noted as having been visibly poisoned by carbosulfan, yet managed to leave the test plot and (though disorientated) reach refuge outside the test area (ca 550 metres away). It was not possible to know if these poisoned birds recovered or died after escaping the experimental plot. Given these points, just like in the anterior experiment, it's necessary consider: i) the number of deaths recorded was not accurate, since poisoned birds may have left the test plot; ii) carbosulfan didn't act as a secondary repellent which interrupts consumption; iii) birds poisoned with carbosulfan had a greater tendency to reach the adjacent forest, where they may be preyed upon by forest species, therefore be hidden from farmers, researchers and hence, public opinion. These points raise questions regarding the principle that carbosulfan may not be used as a substitute for carbofuran. The findings reported here suggest that carbosulfan is probably not an effective alternative to carbofuran.

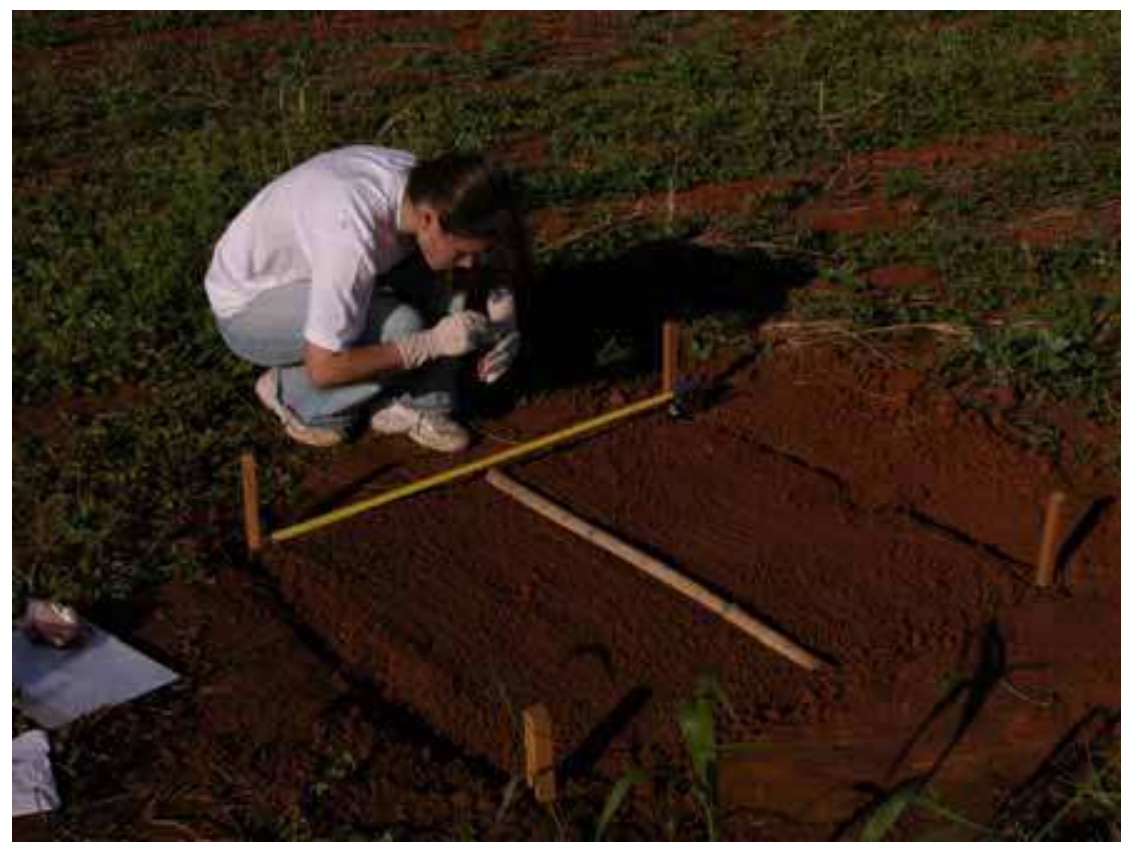

Fig. 8. The distribution of seeds in a plot of the removal experiment. 
In the second assay, the possible repellent effects of methiocarb and carbosulfan were not statically proven. In the treatment with methiocarb, 62 birds died, while similar results were obtained using carbofuran, where 82 birds died. Although fewer birds died when carbosulfan was used, as in the previous trial and experiment, many birds visibly affected by carbosulfan escaped the test plot, making an accurate estimation of mortality difficult.

Although previous experiments have shown the relative efficacy of methiocarb as a secondary repellent to birds (Nelms \& Avery 1997; Avery et al. 2001; Avery 2002), its use in association with carbofuran did not generate results showing it to be a mitigating factor in bird mortality, probably because carbofuran is an extremely toxic pesticide, needing only one treated seed to kill a small or medium sized bird (Almeida et al., 2010a). Thus the toxicity of carbofuran would overrun any of the potentially beneficial effects of methiocarb.

Finally, a third field study, performed in two trials (Almeida et al., 2010b) aimed at evaluating if camouflaged seeds would be less consumed by wild birds in comparison to commercial seeds coated with red-colored rhodamine B and blue seeds (Avery et al., 1999; Hartley et al., 1999; 2000). Seed removal experiments were performed in an area reserved for annual planting of 2.78 ha in southeast of Brazil, where, because of the frequent planting of corn and other cultures, a great deal of granivorous birds could be found at the site. Experimental parcels $(1.5 \times 1.5 \mathrm{~m})$ were randomly distributed in the area circa $50 \mathrm{~m}$ from each other. Seeds from each treatment were disposed in columns over the ground approximately $11 \mathrm{~cm}$ apart (Figures 8,9 and 10). Daily samplings were taken for six days after setup, checking the number of remaining seed in these periods.

Camouflages tested corresponded to the treatments created with the ingredients: liquid dye and powder dye, both colored brown and/ or terracota. The brown-colored powder dye was shaded and thus adjusted by comparison to soil samples from the area. The camouflaged coating elicited by powder dye gave the seeds a dark brown, rugged and opaque surface.

The brown-colored liquid dye was a novel product which attributed to the seeds a smooth, opaque coating, with a shade slightly lighter than the soil in the experiment location. Acrylic glue was added to the dye to enhance adhesion and resistance to camouflaging. Dye and glue were applied to seed as an aqueous solution. Soil of the trials' site was tested as a substitute to artificial dyes and/ or as an accessory camouflaging element, aiming for a higher coincidence in shades of camouflaging colors in relation to the soil.

Camouflages were applied onto seeds with either natural or purplish-red colors previously treated with rhodamine B dye, the product ordinarily and legally used in Brazil to distinguish pesticides-treated seeds.

To evaluate the effect of the search image (Begon et al., 2006) of birds for non-dyed natural grains in comparison to the other treatments, ordinary corn seeds were also used to mimic the situation wild birds find in harvest wastes. Finally, to evaluate the possible aposematic or neophobic effect of blue color, seeds were treated with mid-blue powder dye.

None of the tested treatments had pesticides. Variance analyses of the daily seed permanence in the trials were performed.

Trial 1. To evaluate camouflaged corn seed remaining, natural and rhodamine B-colored, twelve squares with seven rows of seeds each were distributed. Five types of brown camouflage treatments were tested, natural undyed corn and corn with rhodamine B only. The soil under five parcels was weeded and leveled to elicit studying the influence of irregularities and litter on seed removal. The yellow corn grain (natural) and rhodamine Btreated corn columns could be more attractive to the birds, possibly exposing columns close to groups one and two to higher pressure than those more distant. For that reason, the order 
of columns was modified in each parcel so that all treatments could bear the same influence of closeness to the control groups.

Trial 2. The differences in the permanence of wheat, corn and rice seeds with the following treatments were evaluated: i) natural, undyed seeds; ii) rhodamine B-treated seeds; ii) brown powder dye camouflaged seeds; iv) industrialized camouflage with liquid brown dye; v) seeds camouflaged with mid-blue powder dye (Figure 13). Permanence differences among treatment (colors) and botanical species were also evaluated in using twelve experimental parcels (four parcels per grain species). All the parcels were weeded and leveled for making the counting of smaller seeds (wheat and rice) more accurate. Because columns with either natural colors, blue or rhodamine B could be more attractive to birds, the order of the columns was changed in each parcel, exposing the camouflage treatments to influences identical to the closeness to groups with attractive colors.

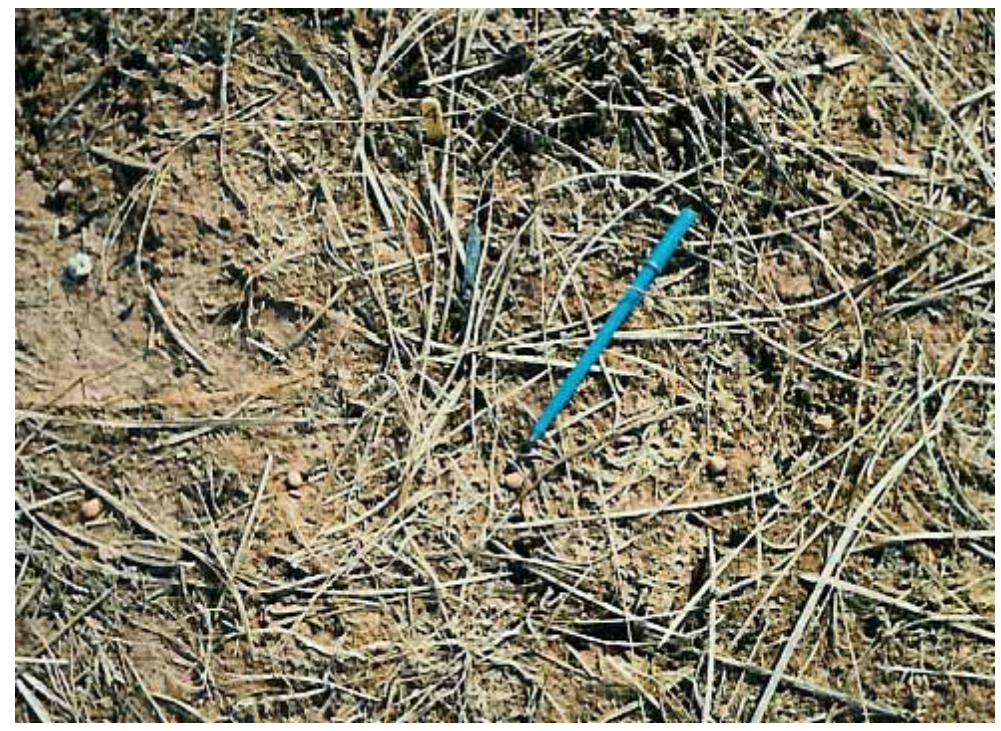

Fig. 9. Corn camouflaged in a plot of the removal experiment

The following findings were obtained: i) the camouflaged seeds were less removed than seeds with rhodamine B and natural colors, noticing that the removing of powder dye camouflaged seeds, standed between $84.5 \%$ to $98 \%$ bellow of those with rhodamine B; ii) the camouflaging was more effective in the presence of irregularities and litter; iii) there was no removal of blue-colored seeds.

Regarding the seed camouflaging, the authors concluded that the method presents low operational and financial costs, does not cause suffering to birds and may be used to diminish bird's mortality by carbofuran in wheat, corn and rice plantations. In concern of the blue seeds, the absolute absence consumption reinforces the theory that there is aversion to this color, according to Avery et al. (1999), Hartley et al. (1999, 2000), with the possible occurrence of aposematism (Joron, 2003) and neophobia (Thomas et al., 2004). Nevertheless, as the usage of blue-colored granular carbofuran had been prohibited because of the mortality of birds caused by the direct ingestion, this color probably should not represent a reliable mitigation method. 


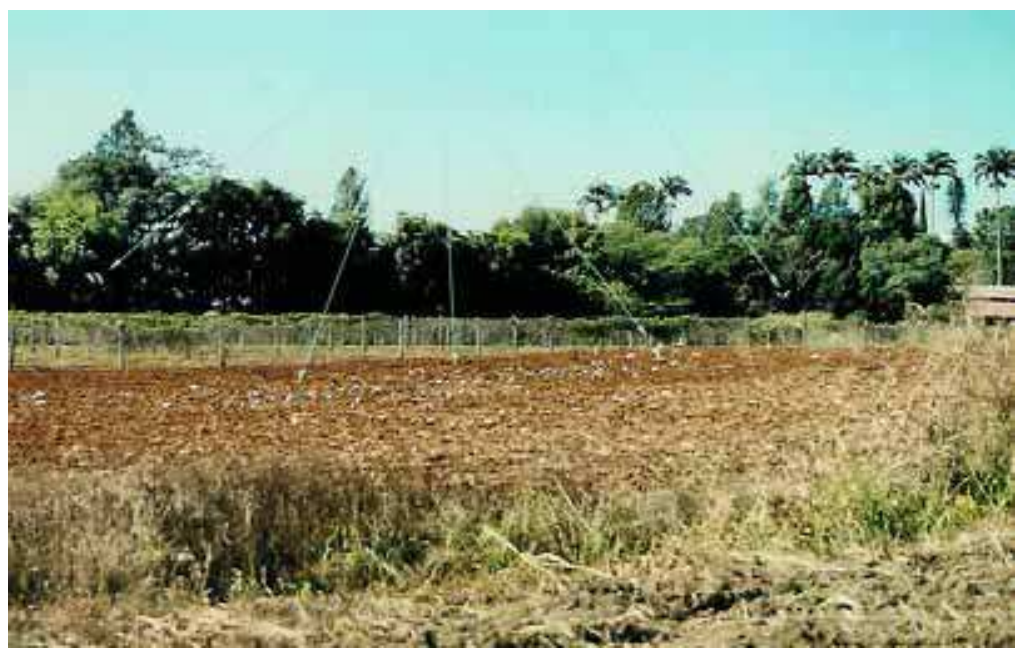

Fig. 10. Domestic pigeons (Columba livia) feeding near to the plots of the removal experiment

\subsection{The impact of poisoning by seeds treated with pesticides in birds}

All the studies realized to compare bird mortality with the possible mitigation methods, like camouflaged, beige color, carbosulfan and methiocarb-treated seeds (Almeida, 2006; Almeida et al., 2010a; Almeida \& Almeida, in press) allowed the evaluation the environmental impact of traditional modes of wheat, corn and rice cultivation used in Brazil, on dry and ploughed soil, with an emphasis on avian mortality caused by seeds dyed using Rhodamine B and treated with carbofuran and carbosulfan (Almeida \& Almeida, in press).

This work partially described above, accounts results from seven field trials, employing $7,339 \mathrm{~kg}$ of seeds sowed in 57.24 hectares (Almeida \& Almeida, in press). The rice and wheat experimentation occurred in similar conditions of Almeida et al., (2010a).

In these experiments, an evaluation of the effect of carbofuran on wild birds was undertaken in these experiments. The mean, standard deviation and confidence interval $(p=0.05 \%)$ of mortality was calculated, and the confidence intervals were computed using the Student's $t$ distribution (Almeida \& Almeida, in press).

Picazuro pigeons (Patagioenas picazuro) and small species such as the eared dove (Zenaida auriculata), ruddy ground dove (Columbina talpacoti) and Chopi blackbird (Gnorimopsar chopi) were the predominant species poisoned by seeds treated with carbofuran and Rhodamine B. All these granivorous bird species are common in rural areas of the south-eastern Brazil.

Granivorous birds represented $97 \%$ of the species poisoned, and the eared dove accounted for $89 \%$ of the total number of individuals found dead. The mortality mounted to 465 birds of 13 species, including partial carcasses and piles of feathers found (feather spots data, Figure 12), which represent birds that were partially consumed or totally removed by avian and mammals predators.

The minimum number of birds poisoned was between 25 and 183 where eared dove flocks were present. The estimated number of birds expected to be poisoned was $77.5 \pm 55.7(\mathrm{n}=6$; standard deviation $=69.6, \mathrm{p}=0.05$ ). Therefore, we would expect an average of approximately 9 deaths per hectare (betw een 2.5 - 15.6 birds per hectare). 


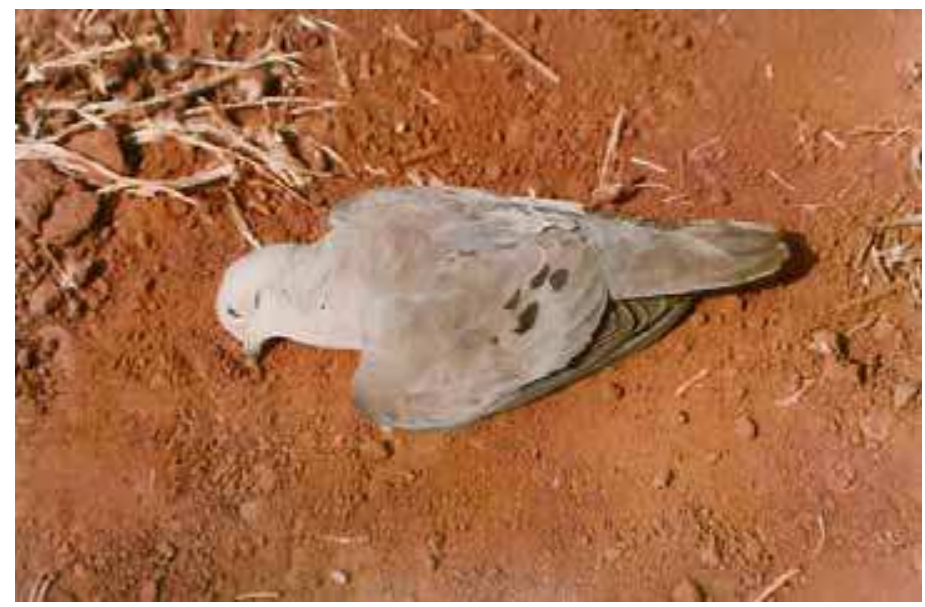

Fig. 11. Eared dove (Zenaida curiculata) killed by ingestion of wheat seeds treated with carbofuran. Eared dove were the most numerous casualties in the plantation experiments.

Aware of the fact that some birds poisoned by carbosulfan escaped into the surrounding habitat before dying, such estimates need to consider that the mortality caused by carbosulfan was probably conservative and not accurate. Moreover, counting did not provide a full tally of secondary poisoning mortality rates, since predators left the area or those carcasses were removed by scavengers before being counted (as described by Mineau 2005).

The estimative of the number of birds potentially poisoned on Brazilian farms are very worrying. Agrotoxins like carbofuran are used on a very large scale in Brazil, and improper use occurs throughout the agricultural landscape. Governmental control is very absent, and millions of hectares are devoted to rice, wheat, and corn production. Species such as the eared dove are abundant in some regions, and they may be both, victims and vectors, effectively passing the agrotoxin legacy up the food chain to predators (some of whom may be rare) as the poisoned doves are predated or scavenged.

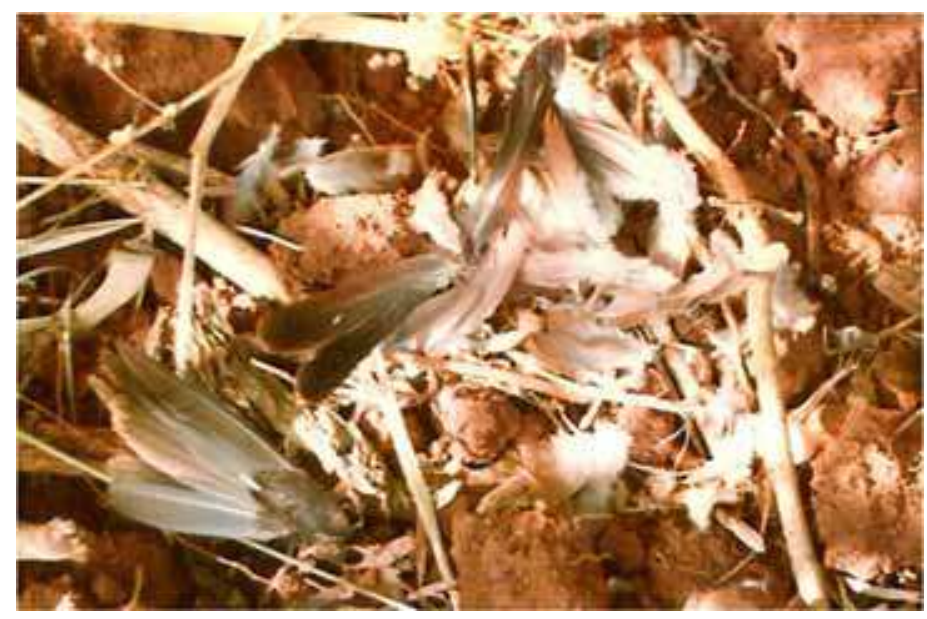

Fig. 12. Activity of predators removing poisoned bird, as evidenced by the pile of feathers. 
The high mortality rates noted in Brazil are equivalent to existing findings (Eisler, 1985; Agriculture Canada, 1993; Mineau et al., 1999; Mineau, 2005) regarding the potential impact carbofuran exposure can have on wild birds.

Given these findings, research must be intensified to evaluate the magnitude of the impact that pesticides are having on Brazilian fauna, since these application methods and formulations have been banned in developed countries, but they are still used in Brazil, and probably in other Latin America countries, on large commercial scales, with government permission. The Brazilian Federal Government should be pressured, since the continued use of carbofuran and Rhodamine B is in conflict with Brazilian Law (Number 7802, July 11, 1989) because they may cause environmental damage.

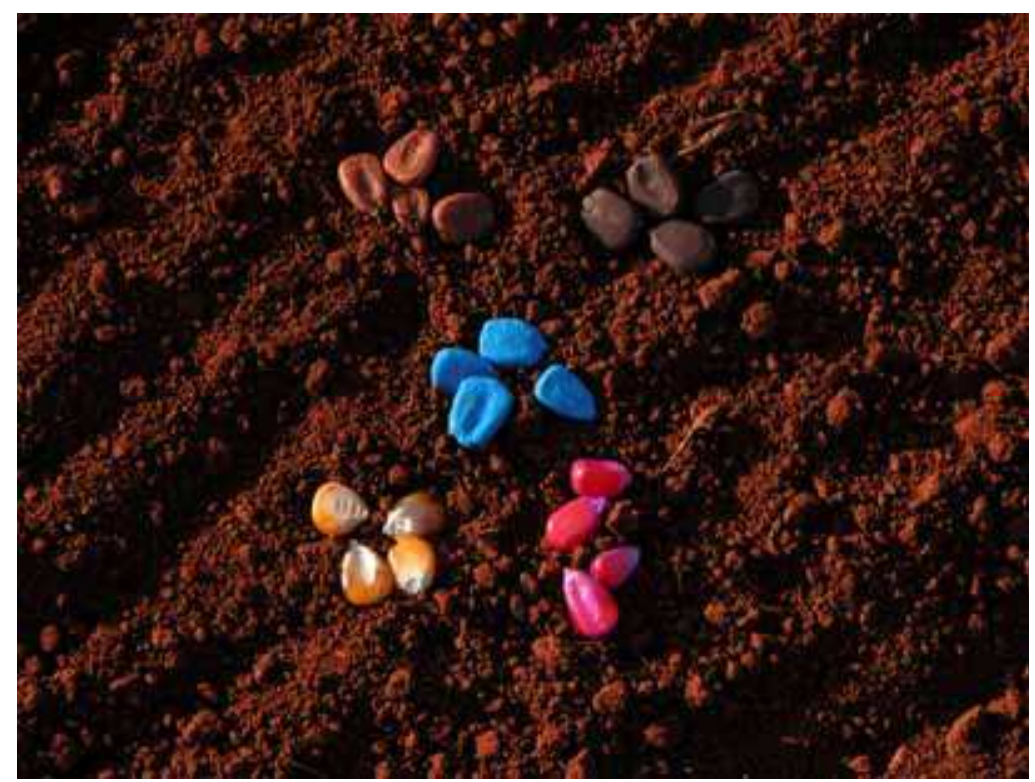

Fig. 13. Seeds treatments tested in the second trial of the removal experiment: camouflaging with industrialized liquid dye (above, left), camouflaging with powder dye (above, right), aposematic mid-blue seed (center), yellow natural corn (below, left), rhodamine B treated seeds (below, right).

\section{How to do camouflaged seeds?}

\subsection{In search of camouflage}

The aim of the first experiment in coloring, which took place in March 1981, was to get a hue close to the soil color, this way, camouflaging the wheat seeds, making them imperceptible to birds. An adequate coverage should effectively camouflage the seeds without affecting germination, having low cost and being non-toxic. On the first experiment with color, we used several different shades of the commercial product called Powder Chess ${ }^{\circledR}$ (hereinafter: powder dye), commonly used in paintings. This product was applied directly to the seed without use of adhesives. 
The chemical composition of this dye was based mainly on iron oxides $(\mathrm{FeO})$ in red and yellow colors, and silicatate colloidal sulfur of the $\mathrm{FeO}$ in blue color, these being the three colors forming the mixtures (camouflage).

The proportions in grams of the pigments, according to the colors of soil, ranged as follows: i) 15 red, 4 yellow: 5 blue, ii) 15 red: 14 yellow: 5 blue, iii) 15 red: 4 yellow: 15 blue. The analysis of the camouflage covers was done visually, comparing them with soil samples from Londrina (PR).

Results showed that, as proportions of each pigment were varied, different tones could be obtained. This fact contributes positively to the camouflage of seeds, enabling it to create coatings with colors that can approach the tone of croplands, from light sandy soils to darkreddish clayey ones. For example, to color $110 \mathrm{~kg}$ of wheat seeds according to a sample of dark red latosol from Londrina-PR, it took $2.4 \mathrm{~kg}$ of mixed colors. The individual quantities of dye to $100 \mathrm{~kg}$ of seed were: 1.5 kilograms of red pigment, $0.40 \mathrm{~kg}$ of yellow pigment, and $0.50 \mathrm{~kg}$ of blue pigment.

\subsection{Camouflage improvements}

Searching for the development of camouflage techniques of seeds treated with syrup of carbofuran, which would provide color and texture similar to the ground, in order to prevent wild birds to recognize them, experiments were carried out in two phases to the selection of appropriate material. Later, the ingredients used for camouflage were selected, according to criteria relevant to seeds germination and their treatment on the machines that apply the Carbofuran syrup. This syrup, composed of Carbofuran, Rhodamine B had a commercial commonly used concentrated suspension of $350 \mathrm{~g} / \mathrm{L}$ (hereinafter: carbofuran syrup).

From all the materials tested, those which did not showed favorable characteristics to the staining process were:

i. Plaster: after the drying process, it had become extremely brittle, loosening up the seed with ease. Besides, while still damp, caused clumping of the seeds during the treatment.

ii. Calcium carbonate: caused clumping of the seeds during the treatment.

iii. Ink (synthetic pigment concentrate, Coral $®$ ): caused clumping of the seeds during the treatment and the drying process took a long time.

iv. Dolomitic limestone with magnesium: when dry, promoted a heterogeneous brittle coverage.

The items which initially showed favorable characteristics to the staining process were:

i. Powder dye, used with water and/ or carbofuran syrup, presented coverage, opacity and appropriate fluidity, as well as quick drying. Did not cause seeds clumping.

ii. Liquid dye (Chess $\left.{ }^{\circledR}\right)$, used with water and/ or carbofuran syrup, presented adequate coverage and smooth, as well as fast drying, however caused higher brightness. Did not cause seeds clumping.

\subsubsection{Material selection for seeds camouflage: phase 1}

This phase started in January 2002 aimed at testing different materials to be possibly used in the process of concealment of the seeds. Features like the coloring capacity of the pigments, its viscosity, seeds agglutination during the treatments, homogeneity and cover resistance were observed, and so the materials deemed suitable were selected for phase 2 . 
The material was tested in phase 1: white plaster, calcium carbonate, powder dye, liquid dye, ink (synthetic pigment concentrate), white acrylic glue, dolomitic limestone with magnesium (Hidrax $\AA$ ) and carbofuran syrup.

In each test (i.e. for every mixture type), a portion of corn ( $100 \mathrm{~g})$ was poured into a plastic cup. In a separate bowl, the material to be tested was mixed up, adding soon after this mixture to the corn. The closed vessel was shaken to simulate the machine where seeds normally receive carbofuran syrup.

Experiments were carried out by varying the proportions of material used, resulting in 75 samples of treated seeds. Samples that showed notable coloring failures were excluded. From 75 experiments, 20 samples of shades of different colors were obtained, going from dark brown to lighter shades, varying also the covering texture of the seed by the mixtures. As for colourings, the best results were obtained with the following proportions: 2 to $4 \mathrm{~kg}$ of dye powder to $100 \mathrm{~kg}$ of seeds, using $2 \mathrm{l}$ of carbofuran syrup and adding 2 to $3 \mathrm{l}$ of water.

Particularly for the red latosol, the best results in coloring tests were shades tones achieved by mixing the following proportions of powder dye (for $100 \mathrm{~kg}$ of seeds, using 2.0 liters of carbofuran syrup): yellow powder $(2.6 \mathrm{~kg})$, red powder $(0.7 \mathrm{~kg})$, brown powder $(0.4 \mathrm{~kg})$, totaling 3.7 kilograms of dyes.

These proportions resulted in a medium brown shade. In order to obtain similar shades of dark or medium brown, the ratios mentioned above must be changed. For a darker ground, it is necessary to use more brown and less yellow, for a lighter soil, one should use more yellow and less brown.

The use of soil as the main element to camouflage corn seed showed good results for colour and texture. The proportions that showed the best results in the laboratory were: $6 \mathrm{l}$ of water, $0.5 \mathrm{l}$ of acrylic glue, $2 \mathrm{l}$ of carbofuran syrup, $50 \mathrm{~kg}$ of sieved soil. The better amount of water to 1 to $2 \mathrm{~kg}$ of powdered dye was 1.5 to 21 (using 21 of syrup) to $100 \mathrm{~kg}$ of seeds. The amount of acrylic glue that brought satisfactory results was 0.21 per $100 \mathrm{~kg}$ of treated seeds with 2 l of syrup.

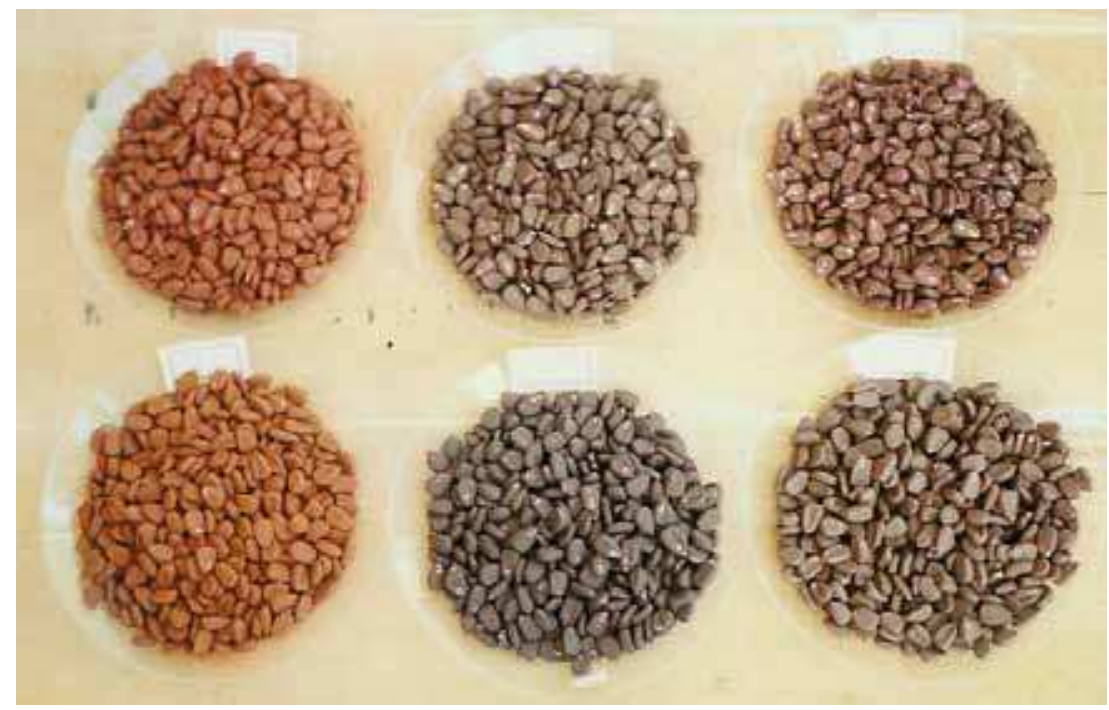

Fig. 14. Prototypes of camouflaged seeds, during the experiment in color and texture. These treatments were selected for the germination experiment 
The mixture of dry soil sieved with acrylic glue and water covering the seeds presented an adequate concealment from the ground as the main element of camouflage. The powder dye mixed with carbofuran syrup and water; and the mix of soil, water, and glue; were the treatments that showed the best colouring results, and the proportions were:

i. soil as a secondary element (untreated seeds): $1 \mathrm{~kg}$ of brown powder dye, $2 \mathrm{l}$ of carbofuran syrup, $4 \mathrm{l}$ of water, $1 \mathrm{l}$ of glue, $30 \mathrm{~kg}$ of sieved soil;

ii. soil as a secondary element (previously carbofuran syrup-treated seeds): $0.3 \mathrm{~kg}$ of brown powder dye, $0.7 \mathrm{~kg}$ of red powder, $2.6 \mathrm{~kg}$ of yellow powder dye, $0.2 \mathrm{l}$ of acrilic glue, $3 \mathrm{l}$ of water, $20 \mathrm{~kg}$ of sieved soil.

\subsubsection{Material selection for seeds camouflaging: phase 2}

This phase, conducted between February and March 2002, aimed to:

i. Determine the ideal minimum proportions of pigments in order to obtain a homogeneous covering of the seeds and complete disappearance of the reddish color caused by the Rhodamine B, present dye in the carbofuran syrup.

ii. Determine the minimum proportions of pigments in order to achieve coloring shades next to the various shades of the soil.

iii. Determine the minimal amount of water to be added to the mix.

iv. Determine the minimal amount of glue, necessary to the best pigment adhesion to the seeds, in the case of seeds already treated with carbofuran syrup.

v. Test the possibility of using soil as the main element or secondary one in the camouflage of seeds.

Corn and pigments (powder dye) were weighed on an analytical balance. Corn seeds were divided into portions of $100 \mathrm{~g}$. Powder dye in brown, yellow and red colors, were divided into different portions from $0.1 \mathrm{~g}$ to $2.0 \mathrm{~g}$.

In each test (i.e. for every mixture type), a portion of corn (100 g) was poured into a plastic cup. In a separate bowl, the material to be tested was mixed up, adding soon after this mixture to the corn. The closed vessel was shaken to simulate the machine where seeds normally receive carbofuran syrup.

When the sifted soil was used, first the seeds received the coverage mentioned above, after, while they were still wet, they received a layer of dry soil. Then, it was added water and glue, and more servings of dry ground, until it reached the proper coverage. Next, the seeds were placed in plastic containers for dry and then received visual analysis.

Treatments (or prototypes) of camouflaging obtained with the ingredients that gave the best results (Figure 14) were evaluated for germination and can be found in the Table 1.

\subsection{Camouflaged seeds in germination tests 3.3.1 Seeds camouflaging with powder dye}

This experiment, conducted in January 1982, aimed to assess whether the pigments used in the process of concealment of seed germination are inhibitors of wheat germination, with or without the presence of carbofuran and the fungicide that is applied in the comercialized seeds.

Eight treatments were established:

i. Red powder dye.

ii. Blue powder dye.

iii. Yellow powder dye. 
iv. Red + yellow powder dye + fungicide + carbofuran .

v. Red + yellow + blue powder dye + fungicide + carbofuran.

vi. Fungicide.

vii. Fungicide and carbofuran.

viii. Control.

For each treatment was prepared two replicates with 49 seeds in each container, spaced about $1.5 \mathrm{~cm}$ apart. The filter paper was adequately dampened and the samples were covered with plastic film to retain moisture, and then placed in an incubator at a temperature of $25^{\circ} \mathrm{C}$. The samples were verified on the fifth day after sowing, when they took an inventory of germinated seeds.

As suggested in Table 1, the powder dye did not cause negative effects on the wheat germination. The experiment suggests the contrary, since it was observed a dark-greenish coloring in the seedlings of 1 to 5 treatments, and also larger seedlings from treatments 4 and 5 , probably due to the nutritional action of the iron element contained in the powder dye.

\begin{tabular}{lc}
\hline \multicolumn{1}{c}{ Treatments } & $\%$ \\
\hline Blue & 100 \\
Red + yellow + fungicide + carbofuran & 100 \\
Red + yellow + blue + fungicide + carbofuran & 100 \\
Fungicide & 100 \\
Control & 100 \\
Red & 98 \\
Yellow & 98 \\
Fungicide + carbofuran & 98 \\
\hline
\end{tabular}

Table 1. Effects of powder dye in the weath germination

\subsubsection{Seeds camouflage with liquid dye}

To know the influence of liquid colorants in the germination of rice seeds, the second experiment was done in February 1982, where the pigments used in the process of seeds concealment, with or without the presence of carbofuran were tested. Twelve treatments were established:

i. Ocher liquid dye.

ii. Orange liquid dye.

iii. Blue liquid dye.

iv. Yellow liquid dye.

v. Black liquid dye

vi. Red liquid dye.

vii. Red, yellow and black liquid dye.

viii. Red, yellow, black liquid dye, and Carbofuran.

ix. Blue, orange, yellow and ocher liquid dye.

x. Blue, orange, yellow, ocher liquid dye, and Carbofuran.

xi. Carbofuran.

xii. Control.

For each treatment four replicates were prepared with 49 seeds in each container, spaced about $1.5 \mathrm{~cm}$ apart. The filter paper was adequately dampened and the samples were covered with plastic film to keep it damp. Seeds were placed in an incubator at a temperature of $25^{\circ} \mathrm{C}$. The samples were verified in the second and fifth days after sowing, when they took an inventory of the seeds and subsequent analysis of nonparametric variance. 
The results of this trial are shown in Table 2 and Figure 15, showing that according to the Kruskal-Wallis test there was heterogeneity $(\mathrm{H}=470, \mathrm{p}=0.000, \mathrm{df}=11)$ on the rice germination under different formulations and formulations combinations of the liquid dye.

The germination varied from $92 \%$ to $100 \%$ on fith day in greenhouse. The grains that less germinated belonged to orange, blue, yellow, and blue + orange + yellow + ocher treatments. This finding prosibly stems from the different composition of organic and inorganic pigments of each dye, which negatively affected the rice germination in the case of treatments $2,3,4$ and 7 .

\begin{tabular}{|c|c|c|c|}
\hline Treatments & Treat & $X$ & $\%$ \\
\hline Black & 5 & 49 & 100 \\
\hline Red & 6 & 49 & 100 \\
\hline Blue + orange + red + yellow + ocher + carbofuran & 8 & 49 & 100 \\
\hline Control & 12 & 49 & 100 \\
\hline Carbofuran & 11 & 48.1 & 98 \\
\hline Ocher & 1 & 47.04 & 96 \\
\hline Red + yellow + black & 9 & 47 & 96 \\
\hline Red + yellow + black + carbofuran & 10 & 47 & 96 \\
\hline Orange & 2 & 46.06 & 94 \\
\hline Blue & 3 & 45.1 & 92 \\
\hline Yellow & 4 & 45.1 & 92 \\
\hline Blue + orange + red + yellow + ocher + carbofuran & 7 & 45.08 & 92 \\
\hline
\end{tabular}

Legend: Treat - treatment number; $\%$ - Percentage of seed germination; $X$-Germination average

Table 2. Effects of liquid dye in the rice germination

\begin{tabular}{|c|c|c|c|c|c|c|c|c|c|c|c|}
\hline 5 & 6 & 8 & 12 & 11 & 1 & 9 & 10 & 2 & 3 & 4 & 7 \\
\hline $\mathrm{i}$ & $\mathrm{i}$ & $\mathrm{i}$ & $\mathrm{i}$ & ii & iii & iii & iii & iv & $\mathrm{v}$ & $\mathrm{V}$ & $\mathrm{v}$ \\
\hline
\end{tabular}

Fig. 15. Variation of the germination average of rice treatments. Arabic figures represent treatments according to Table 2 . Roman figures represent decreasing ranking of the seedlings number. Treatments means united to bars are equal to $5 \%$ of significance level.

Black, red and ocher dyes should be preferred to others in the seeds camouflage, since they don't adversely affect germination. Existing the need for making colors compositions to match the camouflage to the soil, the dyes cited above must be used, as they undo the action of dyes that inhibit germination. This fact could be observed in seed germination of treatment 8 (blue + orange + red + yellow + ocher + carbofuran).

\subsubsection{Improved camouflages}

These new tests started in April 2002, they aimed evaluate whether the ingredients used in the process of improving the camouflage (section 3.1.2.2, Figure 14) would be inhibitors of corn seeds germination. For each treatment, four replicates were prepared with 14 seeds in each container, spaced about $1.5 \mathrm{~cm}$ apart. The treatments were based in the Table 3 , where can be find the ingredients and proportions for each treatments. 
Powder dye, syrup and water

Powder dye, syrup, soil and water

\section{Corn with carbofuran syrup}

Powder dye, liquid dye and water

Powder dye, glue and water

Powder dye, glue, soil and water

\section{\begin{tabular}{|l|l|l|l}
\hline Powder dye & Powder dye & Powder dye & Liqu \\
\hline
\end{tabular}}

Corn with carbofuran syrup and fungicida

Powder dye, liquid dye and water

Powder dye, liquid dye and water

0.4


According to Table 4 and Figure 16, the association (or not) of the liquid and the powder to carbofuran syrup, besides the glue, didn't impair seed germination. By contrast, germination was better with these associations in relation to treatment 1 (carbofuran syrup) and 6 (control). Probably the nutrient action of the powder pigment, rich in iron, favors this result.

\begin{tabular}{lccc}
\hline \multicolumn{1}{c}{ Tratamentos } & Treat & $X$ & $\%$ \\
\hline Carbofuran syrup + p. dye + glue + water & 4 & 13.5 & 96 \\
Carbofuran syrup + p. dye + liq. dye + water & 3 & 11.75 & 83 \\
P. dye + liq. dye + water & 7 & 11 & 78 \\
P. dye + glue + water & 8 & 10 & 71 \\
Carbofuran syrup + p. dye + water + soil & 12 & 8.75 & 62 \\
Carbofuran syrup + p. dye + glue + water + soil & 9 & 6.5 & 46 \\
Carbofuran syrup + fungicide & 2 & 5.25 & 37 \\
Carbofuran syrup & 1 & 4.5 & 32 \\
Carbofuran syrup + fungicide + p. dye + glue + water & 5 & 3.5 & 25 \\
Carbofuran syrup + p. dye + water & 11 & 3.5 & 25 \\
Control & 6 & 3 & 21 \\
Carbofuran syrup + fungicide + p. dye + liq. dye + water & 10 & 3 & 21 \\
\hline
\end{tabular}

Legend: Treat - treatment number; $\%$ - percentage of germination; $X$-média de germinações; $X$ Germination average; P. dye - Powder dye; Liq. dye - Liquid dye

Table 4. Effects of camouflagin in the corn seeds germination, after two days

$$
\begin{array}{|cccccccccccc|}
\hline 4 & 3 & 7 & 8 & 12 & 9 & 2 & 1 & 5 & 11 & 6 & 10 \\
\text { i } & \text { ii } & \text { iii } & \text { iv } & \text { v } & \text { vi } & \text { vii } & \text { viii } & \text { ix } & \text { ix } & \text { x } & \text { x } \\
\hline
\end{array}
$$

Fig. 16. Variation of the germination average of corn treatments in two days. Arabic figures represent treatments according to Table 11. Roman figures represent decreasing ranking of the seedlings number. Treatments means united to bars are equal to $5 \%$ of significance level.

\begin{tabular}{lccc}
\hline \multicolumn{1}{c}{ Tratamentos } & Trat & $X$ & $\%$ \\
\hline Control & 6 & 14 & 100 \\
P. dye + liq. dye + water & 7 & 14 & 100 \\
P. dye + glue + water & 8 & 14 & 100 \\
Carbofuran syrup + p. dye + water + soil & 12 & 14 & 100 \\
Carbofuran syrup + p. dye + water & 11 & 13,75 & 98 \\
Carbofuran syrup + p. dye + glue + water & 4 & 13,5 & 96 \\
Carbofuran syrup + p. dye + liq. dye + water & 3 & 12,75 & 91 \\
Carbofuran syrup + fungicide + p. dye + liq. dye + water & 10 & 12,5 & 89 \\
Carbofuran syrup + p. dye + glue + water + soil & 9 & 12,25 & 87 \\
Carbofuran syrup + fungicide & 2 & 11 & 78 \\
Carbofuran syrup & 1 & 10,5 & 75 \\
Carbofuran syrup + fungicide + p. dye + glue + water & 5 & 9,5 & 67 \\
\hline
\end{tabular}

Legend: Treat - treatment number; \% - percentage of germination; X - média de germinações; X Germination average; P. dye - Powder dye; Liq. dye - Liquid dye

Table 5. Effects of the camouflagin in the corn seeds germination, after five days 


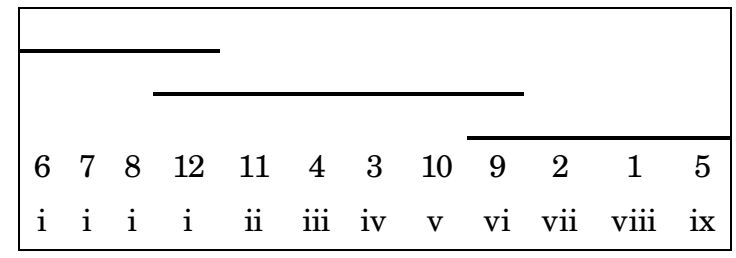

Fig. 17. Variation of the germination averages of corn treatments in five days. Arabic figures represent treatments according to Table 5. Roman figures represent decreasing ranking of the seedlings number. Treatment averages united to bars are equal to $5 \%$ of significance level.

Components that may have inhibited germination in two days were: i) soil associated with carbofuran syrup (treatment 12); i) soil and carbofuran syrup (treatment 9), i) carbofuran syrup and fungicide (treatments $2,5,10$ ), iv) dye powder and carbofuran syrup (treatment $11)$.

With over three days in a germination chamber, the analysis model of variance suggests that the heterogeneity increased $(\mathrm{H}=36.74, \mathrm{p}=0.0001, \mathrm{df}=11)$, with the segregation of three distinct groups (Figure 17). The best averages germination were obtained in the absence of the fungicide and the carbofuran syrup, which inhibited the emergence of the seed embryo, respectively in the first and second scale, in the fifth day at the germination chamber. The dye powder, liquid dye and glue did not inhibit the corn germination.

\section{Camouflaging on the seed treatment machines}

In commercial scales plantations there are large quantities of seeds treated with pesticides such as carbofuran and carbosulfan. Machines made specifically for this purpose are usually used. Aiming to test the compatibility of these machines to camouflage seed, tests were carried out during seven experiments of planting described in Almeida et al. (2010a) and Almeida \& Almeida (in press). In these tests, dyes were added to the carbofuran syrup with or without Rhodamine B, since in certain circumstances, the syrup of carbofuran is found only on sale together with Rhodamine B. More recently, an eighth test was conducted with the objective to test dyes proportions in a new treatment machine, made by another enterprise.

The results of all tests were subjected to visual inspection, observing subsequent drying to coloring, assemblage, texture and adhesion of seeds.

In all seven initial tests, the process of seeds concealment of with powdered or liquid dye was carried out with ease, there were no problems operating the machines by FMC, bad seed coating or agglutination due to the presence of camouflage dyes, except for carbosulfan liquid syrup manufactured by FMC (Marshal 25 ST Brown). This syrup presented showed an irregular coating at a rate of $3 \mathrm{~kg}$ of the syrup to $100 \mathrm{~kg}$ of seeds, being necessary to increase the amount of dye syrup to $5 \mathrm{~kg}$, to have more homogeneity in seeds coverage. The use of camouflage made with powdered dyes was more frequent and was obtained using 4 $\mathrm{kg}$ of powder to $100 \mathrm{~kg}$ of seeds.

The latest tests were performed in June 2002 using the Fersol company machine (Figure 18) that worked best with the proportion of 1.5 liters to 2 liters of a solution of carbofuran syrup with Rhodamine B, and $1.9 \mathrm{~kg}$ of powdered dye to $20 \mathrm{~kg}$ of seeds. 


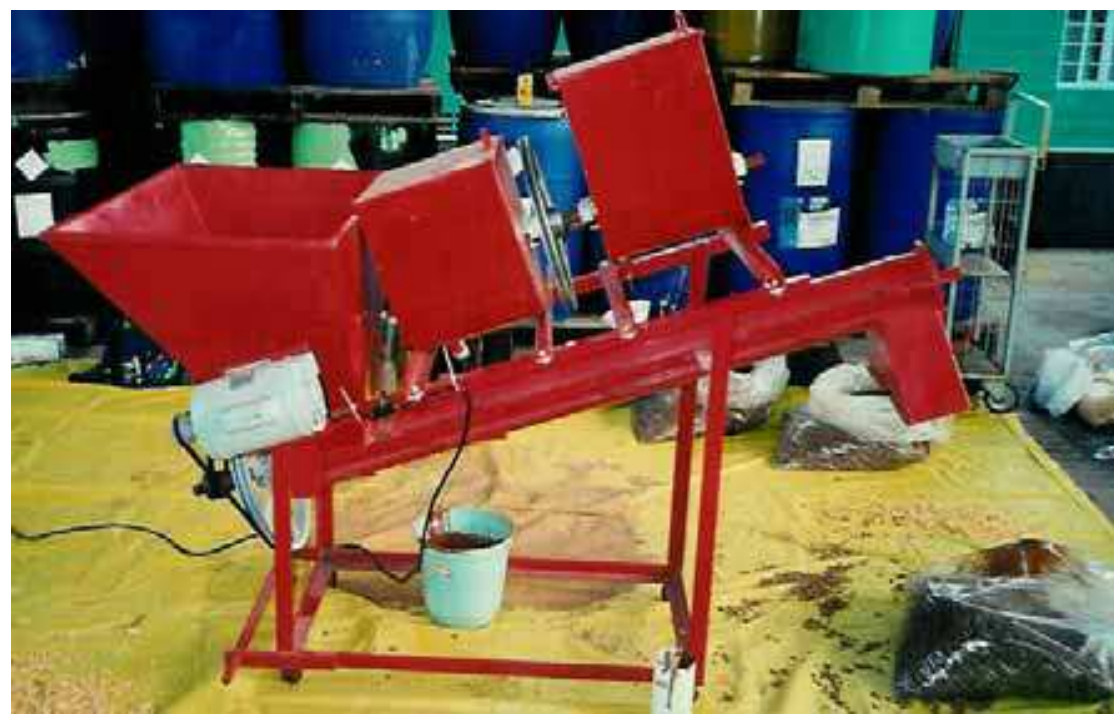

Fig. 18. Seed treatment machine, used to test the application of camouflage in corn seeds. On the floor, in plastic sacks, results of three tests of camouflage by varying the amount of carbofuran syrup, dye powder and water.

Evidently, the color is an important aspect for the camouflage effectiveness (Hartley et al., 1999, 2000), however the presence of Rhodamine B in the application of the camouflaged coating on a commercial scale impair the obtention of the desired brown shades.

During field removal experiment, camouflaged coats previously with similar colors, shades differ in terms of nuances during the time spent in the field. Nonetheless, there were no differences on removal rates among camouflaged seeds. Apparently it may not be necessary having major similarities of shades between camouflaged seeds and the soil to prevent higher consumption rates (Almeida et al., 2010b). Such observation is supported by Merilaita \& Lind (2005), who concluded that the exact similarity of color among the prey and the background is neither enough, nor necessary to minimize the probability of detection by the predator.

In order to have a greater similarity between the camouflage colors and soil, with Rhodamine B in the mixture, it may be necessary to perform two mechanical treatments. First one, to apply carbofuran syrup and when it dries, it proceeds with the camouflaged covers powder or liquids dyes. Once using Carbofuran without Rhodamine B, one can be apply the camouflaged cover concurrently, there being no need for two treatments. Aside from this drawback, the concealment process of seeds is easily obtained using the machines to seed treatment with carbofuran syrup, there being no need for mechanical adjustments.

\section{Discussing on the field performance of the prototypes}

Improved camouflage prototypes, whose ingredients were evaluated in Section 3.1.2.2, were tested for germination (section 3.2.3), regarding the seeds removal by birds in agricultural field (described in section 2, Almeida et al. 2010b) and then using this same experiment, the performance of these prototypes will be discussed, regarding the response of the 
camouflaged covers to weather during five days of exposure, usually when the seeds germinate until the third day after sowing.

The lowest numbers of removals were found for seeds which camouflage was based on powder dye, water, liquid dye, and acrylic glue (Table 5, treatments 3, 4, 5). From the third day on, a significant removal of seeds from treatment 7 (camouflaged with soil, glue and water) happened, as a result of rupture of the coating layer, which exposed the yellow color to the birds. This result, like the seeds removal from treatment 6 (dye powder, soil, glue and water), suggests that soil use as an camouflage ingredient would be inadequate, probably due to less coverage durability to weather with each passing day. In fact, at the end of the trial, the coatings containing soil were broken, leaving the seeds in evidence.

In despite of non significative at 5\%, the highest removal of seeds camouflaged with industrial liquid dye in the treatment 5, shows the importance of superficial grooving in the coverage, attributed to the powder dye in the least removed camouflaged seeds in Trials 1 and 2 (Almeida et al., 2010b). These results suggest that the efficiency of the camouflaging is not only characterized by the brown dye, or because of the similarity of shades between the soil and the seeds, but also by a group of factors attributed to the seed coverage and the background, like opacity and superficial grooving in the seed, and the presence of irregularities and organic matters on the soil surface. In this case, opacity and superficial grooving were provided by the powder dye in the 'home-made' camouflaging (treatments 3 and 4), which, at least to the human view, notably were less conspicuous in the agricultural soil.

In addition to lower rates of seed removal as well as bird mortality, germination rates obtained with the powder dye camouflage (Tables 4 and 5) suggest that in terms of nutrition to the seedlings, the use of these covers can interest the farmer. This part will be appropriate for farmers who wish to camouflage their seeds on their own, without depending on agrochemical companies. Results from tests with materials and methods that have allowed the improvement on the camouflaging methods, including experiments with dye and texture, effects of camouflaged coatings on seed germination and procedures taken during seed treatment with camouflages, dyes and pesticides can be helpful in this issue.

In some trials using powder dye camouflaging without adhesives, as acrylic glue, insectivorous birds were unexpected victims. A cloud of powder released by the seed drill next to the ground was observed during sowing, and it may have poisoned arthropods, which were then consumed by insectivorous birds (Almeida et al., 2010a; Almeida \& Almeida, in press). However, in the process of improving camouflage, the use of acrylic glue prevented the detachment of the dye powder from the seeds. Therefore, adhesives should be required ingredients when there is an association of pesticide to powder camouflage.

The experimentation revealed that the better ingredients to create camouflage covers for seed were: i) powder dye, acrylic glue and water; ii) powder dye and water; iii) powder dye, soil and water; iv) powder dye, liquid dye and water. They show that 'home-made' camouflages with low financial and operational costs present good results in the field, sometimes better than industrial ones.

\section{Conclusions: and so, what matter at now and to the future?}

As research results, in 2003 were granted licenses by the Ministry of Health and the Brazilian Institute of Environment and Natural Resources (BBAMA) for the commercial use of the camouflaged carbofuran syrup without Rhodamine B. 
Currently, camouflaged seeds in the industrial process have more shine and do not have as much surface roughness compared to those of 'hand-made' camouflage. Thus, the effectiveness of the industry seed depends more on the similarity of their colors in relation to the soil. However, probably due to issues associated with large commercial scale production and financial costs, it is common for industrial seed showing clear tone differences from the ground in certain areas, which can compromise the effectiveness of camouflage.

If camouflage seeds fail to effectiveness desired in not attracting birds and are sold at higher prices than seeds stained with Rhodamine B, the tendency is that these seeds are sold only in regions where extremely dense granivorous birds populations threaten to undermine the crops, as soon as they are sowed.

Thus, an appropriate color to the soil and the camouflaged seeds commercialization would be restricted to the occurrence of bird pests outbreaks, as it's noticed in the western of São Paulo state, whose Eared doves population (Zenaida auriculata) have been causing huge losses in agriculture (Bucher \& Ranvaud, 2006; Ranvaud \& Bucher, 2006;).

Many bird species that usually die poisoned by seeds treated with Rhodamine B and carbofuran damage the plantations (Almeida \& Almeida, in press). In regions where there were outbreaks of Eared doves, sometimes farmers deliberately poisoned them offering wheat treated with Rhodamine B and carbofuran (Almeida \& Almeida, in press). So, indeed, many farmers do not care about the accidental plague bird deaths in their crops, and they are probably unaware of the secondary poisoning risks that take predators and scavengers. As the amount of remaining forest in certain agricultural landscapes is so scarce, it may be plausible that the impact of secondary poisoning is jeopardizing the survival of scarce predators populations that depend on forests, with risks of local extinctions of wildlife populations such as mammals: Canidae, Felidae, Mustelidae, Procyonidae, and birds: Accipitridae, Falconidae, Strigidae and Cathartidae.

In order to minimize the risks outlined above, this text strongly emphasizes that, when it comes to planting seeds, the Brazilian government should ban the use of dyes such as Rhodamine B, which are attractive to birds and should at least, make obligatory the use of dyes in similar shades with to the soil in each region.

If according to the Brazilian Federal Decree 4.074 (January 4, 2002) agrochemical defensives must be added to the seeds in association with dyes, to reduce risk of human poisoning, the camouflaging should be employed, substituting Rhodamine B, since the use of carbofuran and Rhodamine B is confliting with Brazilian Law $n^{\circ} 7.802$ (July 11, 1989), which prohibits the registration of pesticides and components that may cause environmental damage.

The Brazilian government should invest more to reduce conflicts between agricultural production and wildlife. Research is needed on methods to mitigate the impacts from various pesticides, as well as their use. Impacts assessments of secondary wildlife poisoning should be performed. There is lack of control on the agrochemicals use, as well as in divulgation of the poisonings in the wildlife. There is lack in the efforts in basic education in concern the conservation and in more sustainable ways of producing food.

The method of camouflaging seeds does not solve the problem of various damage types caused by highly toxic pesticides in the Brazilian agricultural landscape, it is suitable for a particular case, transcript in this text, it equals to a conservationist flag at an iceberg tip, whose enormous base represents huge poisoning problems, which are not visible by most Brazilians, themselves consumers and potential primary victims. 
As the carbofuran, several other pesticide formulations and their application forms have been banned in most developed countries like the U.S. and Canada, however in less developed countries, such pesticides are still produced, used, imported and exported (Richards, in press). The governments of the 'in development countries' should be concerned to monitor the evolution of this knowledge, adopting similar restrictions and mitigation measures.

\section{Acknowledgements}

We also thanks to Florindo Orsi and Antonio C. Zen for technical information; to Antonio Natal Gonçalves for information about colours and paints; to Paulo Y. Kageyama for the germination chambers; to Fersol Indústria e Comércio and to FMC Agricultural Products by the financing research and logistic support.

Alexandre thanks to the Arlinda Coelho and Edisiene de S. Correia, for allowing your dedication to this chapter, during the work time in the SENAI. He also thanks the Fundação de Amparo à Pesquisa do Estado da Bahia (FAPESB) for the post-doctoral fellowship (2319/2009), when part of the text was wrote.

\section{References}

Agriculture Canada (1993). Special review of carbofuran insecticide: effects on avian fauna and value to agriculture. Ottawa: Plant Industry Directorate, 53p. (Discussion Document D93-02).

Almeida, A. de \& Almeida, A. F. de (In press). The environmental impact of farming wheat and rice treated with carbofuran and rhodamine $\mathrm{B}$ on Brazilian wild birds, In: Carbofuran Poisonings of Wildlife: A Global Perspective, N. Richards; P. Mineau (Ed.), John Wiley, Wiley Inc., New York.

Almeida, A. de, Couto, H.T.Z. do \& Almeida, A. F. de (2010a). Camouflaging of seeds treated with pesticides mitigates the mortality of wild birds in wheat and rice plantations. Scientia Agricola, 67, 176-182.

Almeida, A. de, Couto, H.T.Z. do \& Almeida, A. F. de (2010b). Are camouflaged seeds less attacked by wild birds? Scientia Agricola, 67, 170-175.

Almeida, A. de (2006). Camouflaging of seeds treated with agrochemicals as a means of mitigating the environmental impact on wild birds on rice, wheat and corn plantations. PhD Thesis, USP / ESALQ, Piracicaba, 143p.

Avery, M.L. (2002). Avian repellents. In J.R. Plimer, ed. Encyclopedia of agrochemicals, Hoboken (NJ): John Wiley, 1, 122-128.

Avery, M.L., Humphery, J.S., Primus, T.M., Decker, D.G. \& Mcgrane, A. P. (1998). Anthraquinone protects rice seed from birds. Crop Protection, 17, 225-250.

Avery, M.L.; Humphery, J.S.; Decker, D.G. \& McGrane, A.P. (1999). Seed color avoidance by captive red-winged blackbirds and boat-tailed grackles. eburnal of Wildlife Management, 63: 1003-1008.

Avery, M.L. and Mason, J.R. (1997) Feeding responses of red-winged blackbirds to multisensory repellents. Crop Protection, 6, 159-164.

Avery, M. L., Tillman, E. A. \& Laukert, C.C. (2001). Evaluation of chemical repellents for reducing crop damage by Dickcissels in Venezuela. International Journal of Pest Management, 47, 311-314. 
Begon, M., Townsend, C.R. \& Harper, J.L. (2006). Ecology: From Individuals to Ecosystems. Oxford: Blackwell.

Bucher, E.H. \& Ranvaud, R.D. (2006). Eared dove outbreaks in South America: patterns and characteristics. Acta Zoologica Sinica, 52 (Supplement), 564-567.

Calvi, C., De Grazio, JW., Besser, J. \& Mott, D.F. (1976). Protecting Uruguayan crops from bird damage with methiocarb and 4-aminopyridine. Bird Control Seminars Proceedings. Lincoln: University of Nebraska, p. 255-258.

Cuthill, I., Steves, M., Sheppard, J., Maddocks, T., Párraga, A.C. \& Troscianko, T.S. (2005). Disruptive coloration and background pattern matching. Nature, 434, 72-74.

Demattê, J.A.M., Epiphanio, J.C.N. \& Formaggio, A.R. (2003). Influência da matéria orgânica e de formas de ferro na reflectância de solos tropicais. Bragantia, 62, 451-464.

Dolbeer, R.A., Avery, M.L. \& Tobin, M.E. (1994) Assessment of field hazards to birds from methiocarb applications to fruit crops. Pesticide Science, 40, 147-161.

Eisler, R. (1985). Carbofuran hazards to fish, wildlife and invertebrates: a synoptic review. U.S. Fish and Wildlife Service Biological Report, 85, 36.

Frankel, K., Sousa, S., Cowan, R. \& King, M. (2004). Concealment of the warfighter's equipment through enhanced polymer technology. In Army Science Conference 24. Proceedings. Orlando: U.S. Army, p. 13-16.

Hart, N.S. (2001). The visual ecology of avian photoreceptors. Progress in Retinal Eye Research, 20, 675-703.

Hartley, L., Waas, J., O'connor, C. \& Matthews, L. (1999). Colour preferences and coloured bait consumption by weka Gallirallus australis, an endemic New Zealand rail. Biological Conservation, 93, 255-263.

Hartley, L., O'connor, C., Waas, J. \& Matthews, L. (2000). Colour preferences in North Island robins (Petroica australis): implications for deterring birds from poisonous baits. New Zealand Journal of Ecology, 23, 255-259.

Joron, M. (2003). Aposematic coloration, In: Encyclopedia of Insects, Carté, R.T.; Resh, V.H., (Ed.), 39-45, Academic Press, New York, USA.

Merilaita, S. (2003). Visual background complexity facilitates the evolution of camouflage. Evolution, 57, 1248-1254.

Merilaita, S. \& Lind, J. (2005). Great tits (Parus major) searching for artificial prey: implications for cryptic coloration and symmetry. Behavioral Ecology, 17: 84-87.

Merilaita, S.; Tuomi, J. \& Jormalainen, V. (1999). Optimization of cryptic coloration in heterogeneous habitats. Biological eburnal of the Linnean Society, 67: 151-161.

Mineau, P. (1993). The hazard of carbofuran to birds and other vertebrate wildlife. Technical Report Series 177, Environment Canada, Canadian Wildlife Service, Ottawa. Xxii, $96 \mathrm{pp}$.

Mineau, P. (2005). Direct losses of birds to pesticides: beginnings of a quantification. Forest Service General Technical Report PSW-GTR-191, 2, 1065-1070.

Mineau, P., Fletcher, M.R., Glaser, L.C., Thomas, N.J., Brassard, C., Wilson, L.K., Elliott, J.E., Lyon, L.A., Henny, C.J., Bolinger, T. \& Porter, S.L. (1999). Poisoning of raptors with organophosphorus and carbamate pesticides with emphasis on Canada, US, and UK. Journal of Raptor Research, 33, 1-37.

Moran, S. (2001). Aversion of the feral pigeon and the house sparrow to pellets as sprouts treated with commercial formulations of methyl anthranilate. Pest Management Science, 57, 248-252. 
Nelms, C.O. \& Avery, M.L. (1997). Reducing bird repellent application rates by the addition of sensory stimuli. International Journal of Pest Management, 43, 187-190.

Ranvaud, R. \& Bucher, E. H. (2006). Explosions of the eared dove: the unique case in southeast Brazil. Acta Zoologica Sinica, 52 (Supplement), 568-569.

Richards, N. (In press). Conclusions, recommendations and the way forward, In: Carbofuran Poisonings of Wildlife: A Global Perspective, N. Richards; P. Mineau (Ed.), John Wiley, Wiley Inc., New York.

Richards, N. \& Mineau, P. (In press). Preface, In: Carbofuran Poisonings of Wildlife: A Global Perspective, N. Richards; P. Mineau (Ed.), John Wiley, Wiley Inc., New York.

Schmidt, V., Schaefer, H.M. \& Winkler, H. (2004). Conspicuousness, not colour as foraging cue in plant-animal signaling. Oikos, 106, 551-557.

Sick, H. (1997) Ornitologia Brasileira. Rio de Janeiro: Nova Fronteira, 862p.

Tobin, M.E. (2002). Developing methods to manage conflicts between humans and birdsthree decades of change at the USDA National Wildlife Research Center. In: Vertebrate Pest Conference, Davis. Proceedings. Davis: University of California, 20, 91-96.

Thomas, R.J.; Bartlett, L.A.; Marples, N.M.; Kelly, D.J.; Cuthill, I.C. (2004). Prey selection by with birds can allow novel and conspicuous color morfhs to spread in prey populations. Oikos, 106, 285-294.

Zug, G.R., Vitt, L.J. \& Caldwell, J.P. (2001) Herpetology: An Introductory Biology of Amphibians and Reptiles. San Diego: Academic Press. 


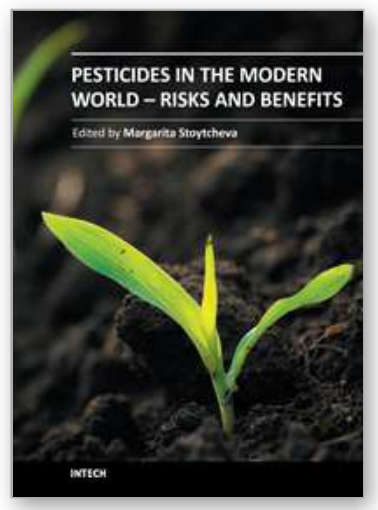

\author{
Pesticides in the Modern World - Risks and Benefits \\ Edited by Dr. Margarita Stoytcheva
}

ISBN 978-953-307-458-0

Hard cover, 560 pages

Publisher InTech

Published online 03, October, 2011

Published in print edition October, 2011

This book is a compilation of 29 chapters focused on: pesticides and food production, environmental effects of pesticides, and pesticides mobility, transport and fate. The first book section addresses the benefits of the pest control for crop protection and food supply increasing, and the associated risks of food contamination. The second book section is dedicated to the effects of pesticides on the non-target organisms and the environment such as: effects involving pollinators, effects on nutrient cycling in ecosystems, effects on soil erosion, structure and fertility, effects on water quality, and pesticides resistance development. The third book section furnishes numerous data contributing to the better understanding of the pesticides mobility, transport and fate. The addressed in this book issues should attract the public concern to support rational decisions to pesticides use.

\title{
How to reference
}

In order to correctly reference this scholarly work, feel free to copy and paste the following:

Alexandre de Almeida, Hilton Thadeu Zarate do Couto and Alvaro Fernando de Almeida (2011). Camouflage of Seeds, a Control Method of the Bird Mortality in Grain Crops, Pesticides in the Modern World - Risks and Benefits, Dr. Margarita Stoytcheva (Ed.), ISBN: 978-953-307-458-0, InTech, Available from: http://www.intechopen.com/books/pesticides-in-the-modern-world-risks-and-benefits/camouflage-of-seeds-acontrol-method-of-the-bird-mortality-in-grain-crops

\section{INTECH}

open science | open minds

\author{
InTech Europe \\ University Campus STeP Ri \\ Slavka Krautzeka 83/A \\ 51000 Rijeka, Croatia \\ Phone: +385 (51) 770447 \\ Fax: +385 (51) 686166 \\ www.intechopen.com
}

\author{
InTech China \\ Unit 405, Office Block, Hotel Equatorial Shanghai \\ No.65, Yan An Road (West), Shanghai, 200040, China \\ 中国上海市延安西路65号上海国际贵都大饭店办公楼 405 单元 \\ Phone: +86-21-62489820 \\ Fax: +86-21-62489821
}


(C) 2011 The Author(s). Licensee IntechOpen. This is an open access article distributed under the terms of the Creative Commons Attribution 3.0 License, which permits unrestricted use, distribution, and reproduction in any medium, provided the original work is properly cited. 